\title{
Recent advances in pediatric anesthesia
}

\author{
Josef Holzki \\ Emeritus, Department of Paediatric Anaesthesia, Children's Hospital Cologne, Germany
}

Writing about advances in a field of medicine normally includes some pride about progress which one was witness to or even a participant in. The younger one is, the more enthusiastically every advance is lauded and welcomed. This is human nature and nothing to be complained about. However, when anesthesiologists, having worked and struggled in the field of pediatric anesthesia for about 40 years, look back to past advances, a more realistic, even painful picture comes to mind. There was a price which a considerable number of patients had to pay for progress, ruined health or even death. This experience of decades of practice is rarely presented in the literature but should not be forgotten when we proudly remember advances in pediatric anesthesia. (Korean J Anesthesiol 2011; 60: 313-322)

Key Words: Advances pediatric regional intravenous anesthesia.

The review of the literature in regard to recent advances in pediatric anesthesia can be very frustrating from a scientific point of view.

The literature as well as the lectures at scientific meetings are full of statements that certain techniques, drugs or tools "are becoming more popular" in pediatric anesthesia. What do these statements mean scientifically? Do the new techniques, drugs or tools serve the needs of our pediatric patients, or rather the wishes of parents, caretakers or anesthesiologists - or is the socalled popularity simply based on current fashions?

A review article like this cannot cover the entire field of pediatric anesthesia, which would fill the volume of a textbook, but I shall try to differentiate between current popularity and scientifically proven advances in important sub-fields of pediatric anesthesia.

\section{Recent Guidelines in Pediatric Cardiopul- monary Resuscitation (CPR)}

Cardiac arrest algorithms are of particular importance in pediatric anaesthesia since they are life saving when cardiac arrest occurs in otherwise healthy children during anesthesia due to unexpected adverse events. The last ILCOR (International Liaison Committee on Resuscitation) universal arrest algorithm was published in 2005, covering pediatric CPR as well [1].

Guidelines do not necessarily reflect the most refined clinical standards. But there has been an outspoken attempt to find a consensus among a group of interested specialists - to give advice for a specific procedure, in this case CPR. ILCOR has tried to find a consensus after going through a scientific evaluation process and has summarized conclusions

Received: September 7, 2010. Accepted: October 26, 2010.

Corresponding author: Josef Holzki, M.D., Emeritus, Department of Paediatric Anaesthesia, Children's Hospital Cologne, Beienburger, Str. 45, D-51503, Roesrath, Germany. Tel: 49-2205-8983-5, Fax: 49-2205-8983-5, E-mail: josef.holzki@arcor.de

(c) This is an open-access article distributed under the terms of the Creative Commons Attribution Non-Commercial License (http:// creativecommons.org/licenses/by-nc/3.0/), which permits unrestricted non-commercial use, distribution, and reproduction in any medium, provided the original work is properly cited. 
and recommendations. This evaluation process is aimed at establishing more clinical evidence for future guidelines.

This doesn't mean that older guidelines are dangerous. However, more science is involved in the newest guidelines, probably making them a better choice. Too many parts of the CPR-process have not been thoroughly investigated. Therefore, the clinical experience of clinicians practicing CPR is very important.

A good example of a randomised study that is missing the answer we need for the clinical use of CPR was one carried out in a randomized, double blind manner as a rescue therapy for in-hospital cardiac arrests in children [2]. A tenfold higher dose of adrenaline ( $100 \mu \mathrm{g} / \mathrm{kg})$ was given to children during CPR when the standard dose of $10 \mu \mathrm{g} / \mathrm{kg}$ failed. The authors couldn't identify any benefit of the tenfold higher dose, which might be worse than the standard dose, and they do not recommend such high doses. This finding doesn't offer any help in clinical situations where we double, then triple or quadruple the standard dose of adrenaline when the heart doesn't respond to CPR. Anaesthesiologists with decades of clinical experience in CPR know that some children respond to high doses of adrenaline, often showing good neurological outcome, if dosing is elevated in a stepwise fashion. A similar experience was reported by Todres and Goetting [3,4]. An immediate tenfold increase in adrenaline when the standard dose of $10 \mu \mathrm{g} / \mathrm{kg}$ fails, reflects unwise clinical practice. The reason why higher doses of adrenaline are helpful is probably due to inadequate cardiac compression or extraordinarily severe acidosis, preventing adrenaline from acting. Relying on their vast clinical experience, rescuers should use higher doses of adrenaline before quitting resuscitation, as it will help in a fair number of cases.

\section{What is new in the guidelines of $2005 ?$}

A key point in the guidelines appears to be the importance of shortening no-flow times of the circulation during cardiac arrest by reducing ventilation periods and shortening check times for the presence of a pulse or for effects of defibrillation. The success of uninterrupted heart compressions by reducing ventilation periods without disturbing other vital parameters was demonstrated in a recent study using manikins [5].

Interruption of chest compressions during CPR must be minimized!!

\section{Main differences from older CPR-models}

Children over eight years of age are treated like adults.

- A compression - ventilation ratio of $30: 2$ at all ages except newborns should be performed by a single rescuer.

- In newborns and infants a $15: 2$ compression/ventilation ratio should be used in a 2-rescuer situation.

- In children, the lower third of the sternum should be used for chest compression since it may generate a higher blood pressure than the usual compression of the middle of the chest.

- After one defibrillation, CPR should be continued immediately without rhythm analysis, to prevent longer no-flow times. After two minutes of CPR, the next shock should be applied.

- In a two-rescuer situation, the airway should be secured (tracheal tube, LMA, combitube) and ventilation carried out at a rate of $8-10 / \mathrm{min}$. Chest compressions $(100 / \mathrm{min})$ should not be interrupted by ventilation!

- Despite lack of scientific evidence in human studies, the routine use of vasopressors (adrenaline) is recommended.

- There is insufficient evidence to use vasopressin alone or in combination with adrenaline.

- Reversible conditions (hypoxia, hypovolemia) should be corrected immediately!

- A 10-fold higher dose of i.v. adrenaline is not recommended in routine CPR when a standard dose has failed.

- When intra-tracheal application is unavoidable, $10 \mathrm{x}$ the i.v. dose should be given.

- Atropine was not associated with any benefit in CPR.

- Sodium bicarbonate is not recommended for routine use but might be considered for life-threatening hyperkalemia or cardiac arrest associated with hyperkalemia or for preexisting severe metabolic acidosis or tricyclic antidepressant overdose.

- Magnesium should be given only for hypomagnesemia and torsades de pointes.

- In hypovolemia, isotonic crystalloids? have the same effect as albumin.

\section{Recent guidelines in neonatal resuscitation}

Resuscitation Guidelines for term and preterm infants were included in the ILCOR guidelines of 2005. Experimental and clinical research, which changed different components of $\mathrm{CPR}$, were introduced. Concentration on continuous cardiac compression with little interruption by ventilation, and pulse checks or rhythm analysis after defibrillation, is mandatory, as in adult patients. The importance of keeping the babies warm, and avoiding suctioning and airway manipulations as a general rule in order to minimize injury to the airway and lung, are the top points of emphasis? in the new guidelines. The response to ventilation should be assessed by the heart rate and oxygen supply modified according to gestational age. Rescuers have to keep in mind that their actions in the first minutes of the life of a neonate are vital for the entire future life of the neonate [6]. 


\section{Regional Anesthesia}

Probably the most important general achievement in pediatric anesthesia during the last few years, one influencing all areas of pediatric anesthesia, was the re-introduction of regional techniques in the late 1980s. This was possible due to the advent of safe regional anesthetics (bupivacaine) and the better understanding of the skeletal anatomy of infants and children, leading to a safer dosing [7]. Although bupivacaine remains the most commonly used local anesthetic in infants and children, and has the longest duration of action, levobupivacaine and ropivacaine, according to the literature, provide a reduced risk of neurologic and cardiac toxicity [8].

General anesthesia combined with regional techniques expose children of all ages to less intravenous and inhalational anesthetics and analgesics, keeping them almost free of nausea, vomiting, itching or unnecessary sedation compared to the sole use of general anesthesia. Being fully awake and being able to drink early after surgery, and having no problems breathing even after prolonged surgery, are great advantages and are appreciated by children and parents. With the placement of epidural catheters, analgesia can be prolonged for days postoperatively.

Peripheral nerve blocks and caudal anesthesia are very safe, but great caution is always mandatory to avoid side effects. Safety depends greatly on the sufficient training of pediatric anesthesiologists. The well trained pediatric anesthesiologist tries to avoid risky modes of application of regional anesthetics and is always prepared to treat dangerous side effects (overdoses, intravenous administration induced seizures, tip displacement of epidural catheters, centrally located abscesses).

Portable ultrasound equipment of high quality has considerably added to anatomical knowledge and the safety of nerve blocks. Most importantly, the visualization of tips of epidural catheters, in particular when advanced into the thoracic area, locates epidural catheters with high reliability. There is vast clinical evidence that ultrasound guided regional anesthesia is as advantageous as in adult practice. However, this view is supported only by a small series of investigations in pediatric patients. Nevertheless, a long period of training with supervision by experienced instructors, in particular when placing neuraxial blocks, appears to be indispensable [9]!

This was documented in an exemplary way in two important studies. The first, a retrospective study with more than 24,000 patients, had an unacceptably high rate of severe side effects including death and paraplegia. The blocks were performed by physicians with an unknown extent of experience [10]. The second study, which was prospectively performed by experienced pediatric anesthesiologists, showed only minor side effects in a similar number of patients [11]. The message of these two studies makes it very clear that un-experienced anesthesiologists should avoid placing neuraxial blocks!

Compared to effects in older children, the duration of local anesthetics is considerably shorter in infants. [[In spinal anesthesia in ex-prematures, an important way to avoid postoperative apnea is to recall that MEANING IS UNCLEAR]] the duration of bupivacaine lasts only about one hour, which makes it mandatory to have the operation performed by very experienced surgeons who are able to finish the intervention during this time window.

The introduction of electrical epidural stimulation for confirmation and segmental localization of epidural catheters, combined with ultrasound guidance for assessing the site of needle puncture and catheter advancement from the caudal to the thoracic area, seems to add extra safety to epidural catheter placement [12].

A very recent paper reviewed an increasing amount of literature about ultrasound-guided techniques for neuraxial blocks in children [13]. Ultrasound imaging seems to reliably predict the anatomical depth of loss of resistance. This is an important aid to safely placing epidural catheters, but the putative overall advantage of ultrasound guided placement of epidural catheters needs to be supported by larger studies (although documented outcomes already suggest that there are benefits).

To quantify side effects of drugs that are ancillary to neuraxial blocks - drugs such as clonidine, dexmedetomidine, ketamine and opioids - larger epidemiological studies are needed to avoid the re-introduction of unnecessary side effects like sedation, itching and vomiting.

\section{Inhalational Anesthesia}

Halothane was introduced into clinical practice in 1956 as the first non-inflammable anesthetic. Shortly before isoflurane and enflurane appeared on the market in 1966, Edmond I Eger had developed a stimulus-response test for assessing anesthetic potency of the different agents, namely Minimum Alveolar Concentration, MAC [14]. It is still the best test to compare inhalational anesthetics today [15], and is well known in the community of anesthesiologists.

Since sevoflurane was released on the Japanese market in 1992 and approved by the US Food and Drug Administration (FDA) in 1995, it has become the induction agent of choice in most countries in the world that can afford the higher price compared to the extremely cheap halothane.

Sevoflurane is considered to be an improvement in inhalational anesthesia according to all modern textbooks of anesthesia. The most striking advantage of sevoflurane is the ease of induction of anesthesia and the rather short recovery 
Table 1. Doses of Halothane and Sevoflurane in Vol\% and MAC of Studies Comparing Cardiovascular Side Effects of Both Agents

\begin{tabular}{|c|c|c|c|c|c|c|}
\hline & & Halothane vol\% & MAC & Sevofl. vol\% & MAC & $\%$ Overdose \\
\hline Piat & 1994 & 3.5 & (3.9) & 7.0 & (2.8) & $43 \%$ \\
\hline Epstein & 1995 & 5.0 & (5.6) & 7.0 & (2.8) & $100 \%$ \\
\hline Nakae & 1995 & 1.6 & (1.7) & 4.5 & (1.8) & $0.6 \%$ \\
\hline Sarner & 1995 & 4.5 & (5.0) & 7.0 & (2.8) & $78 \%$ \\
\hline Lerman & 1996 & 4.3 & (4.8) & 7.0 & (2.8) & $71 \%$ \\
\hline Sigston & 1997 & 5.0 & (5.6) & 8.0 & (3.2) & $75 \%$ \\
\hline
\end{tabular}

MAC values according to Coté et al. [29]. Halothane 0.9 vol, sevoflurane 2.5 vol\%. Vaporizer dials are shown in vol\% according to published articles.

Table 2. Output of Halothane-vaporizers and Compared to Sevoflurane-vaporizers

\begin{tabular}{lcc}
\hline Agent & $\begin{array}{c}\text { Max. vaporizer } \\
\text { output }\end{array}$ & $\begin{array}{c}\text { Max. possible MAC } \\
\text { multiples }\end{array}$ \\
\hline Halothane & 5 vol\% & 5.75 \\
Sevoflurane & 8 vol\% & 2.42 \\
\hline
\end{tabular}

times. The side effects, however, are manifold and alarming. It is often difficult to rapidly reach a deep level of anesthesia with sevoflurane as the sole agent [16]. It can cause conduction abnormalities and should be used with great caution in children with severe ventricular outflow obstruction $[17,18]$.

Its supposedly far better cardiovascular stability in comparison with halothane is described in countless articles and comprehensively in all textbooks of pediatric anesthesia. However, it is more than astounding that the supposedly most important advantage of sevoflurane, cardiovascular stability in comparison with halothane, is not supported by the literature [19-24]. Authors of important studies, apparently comparing vaporizer dials instead of MAC values, addressed this problem in an editorial [25], but they did not respond to the questions raised.

Comparing dialed vol\% with calculated MAC values in some frequently quoted studies in which volume percent of the inhalational agents were documented, show the discrepancy of effective doses applied (Table 1).

Only a few studies such as Nakae's compared equipotent MAC values and found no difference in cardiovascular function between the two inhalational agents [21]. Numerous studies have apparently compared the maximum output of vaporizers of the respective anesthetic agents for induction instead of MAC equivalents (Table 2) [26].

The perioperative cardiac arrest registry showed a decrease in arrests from 1994 to 1997 compared to 1998-2004 [27]. Arrests due to medication had decreased from $37 \%$ to $18 \%$. It was speculated that the lower incidence of medication related arrests were due to less frequent use of halothane; but no evidence was given for this assertion. However, the explanation for this decrease might not be related to the better safety profile of sevoflurane but to the vaporizer, not permitting such high MAC multiples as for halothane, and indicating that halothane was regularly overdosed, as documented in references 19, 20, and $22-24$

The scientific approach to comparing halothane and sevoflurane becomes even more complicated when nitrous oxide is added. Nitrous oxide reduces the MAC of halothane by $70 \%$ but reduces it only by $20 \%$ for sevoflurane [28]. This makes the most frequently quoted echo-cardiographic study, supposedly demonstrating less hemodynamic depression in sevoflurane compared with halothane at 1.5 MAC, irrelevant. [[Due to the addition of nitrous oxide 2.1 MAC halothane with 1.7 MAC sevoflurane were compared and not 1.5 MAC of both agents [30]. MEANING IS UNCLEAR.]].

The high rate of cardiac arrhythmias during halothane anesthesia compared to sevoflurane was observed early and addressed in many studies. Arrhythmias under halothane have been known for many years and are considered in clinical practice as an early sign of overdosing. Again, with the addition of nitrous oxide to 5 vol\% halothane and 8 vol\% sevoflurane, an unbelievably high rate of arrhythmias under halothane $-62 \%$ - was recorded in one of the most frequently quoted articles comparing both agents [29]. This is an overdose of halothane by about $100 \%$, an even that is not encountered in regular clinical practice. In clinical practice it is evident that sevoflurane is less arrhythmogenic than halothane and thus preferable in patients with arrhythmias, but this cannot be proven by such vague studies.

Considering the many studies mentioned above, which were not able to demonstrate convincing hemodynamic advantages of sevoflurane compared to halothane, a key question has to be raised despite the high popularity of sevoflurane: why have we, the majority of the community of pediatric anesthesiologists, accepted the results of these inadequate, although peer reviewed studies? Were the peers reviewing for the journals and accepting these studies for publication, not familiar with the well known system of MAC? Is there an unidentified bias that is operative in too many pediatric anesthesiologists, that 
doesn't permit them to see these striking overdoses? There was no reaction from authors or journals when these errors were published in 1999.

This development shows that we, the pediatric anesthesiologists, have to take the utmost caution when new drugs for children are released on the market. Or - I hesitate to say it - do scientific journals need more experienced peer reviewers for subspecialties?

Other serious side effects of sevoflurane, seizures and muscle stiffness, and sometimes impeding intubation, have not, to date, been investigated thoroughly, although the problem is well documented in the literature.

A high incidence of seizures $(>6 \%)$ was reported in Japan in 1992 when 8 vol\% of sevoflurane was used for mask induction without premedication with anticonvulsants [31]. Lowering the concentration of sevoflurane to 6 vol\% for induction reduced the incidence of seizures considerably. For this reason, many anesthesiologists don't use doses higher than 6 vol\%.

Since 1999, convincing studies have been presented, showing that sevoflurane causes real seizures and not just seizurelike movements [32]. On positron emission tomography, ictally increased regional blood flow during epileptiform EEG discharges as well as interictally decreased blood flow were documented as real seizures in healthy volunteers receiving sevoflurane [33]. Regarding pediatric patients, seizures in association with moderate hyperventilation was observed in a very high percentage of patients receiving sevoflurane [34]. These findings increased awareness of this important problem in pediatric anesthesia. Also, parents continued to complain about temporary personality changes in children taking sevoflurane. These findings were supported by a more recent study showing that sevoflurane consistently elicits dose-dependent epileptiform discharges at surgical levels of anesthesia [35].

In 2005 a French group cautioned against the use of high doses of this agent in pediatric patients [36] and gave some practical recommendations to protect against the epileptogenic activity of sevoflurane: avoiding hypocapnia particularly in infants, using premedication with diazepines (e. g. midazolam), adding nitrous oxide for a protective effect, and supplementing sevoflurane with narcotics in order to reduce the concentration of sevoflurane during anesthesia, thus reducing epileptiform activity.

[[The quantification of epileptiform encephalographic activity may further minimize the occurrence of non-convulsive seizures [37]. LOGIC/MEANING IS UNCLEAR.]].

Two questions remain: (1) how can we best sedate the "howling cortex" [38]; (2) could seizure activity elicited by sevoflurane kindle epilepsy-like, febrile, infection-related seizures?
The answer to the first question is: today there is greater awareness of seizure activity due to the use of sevoflurane, and it can be reduced or prevented [36-38]. Reduction/prevention methods should be practiced.

However, it is presently impossible to answer the second question since large epidemiological studies are needed to support such an assumption.

Sevoflurane was thought to have little effect on liver function because its biochemical degradation did not lead to trifluoroacetyl proteins. However, as early as 1992, hepatic injury after sevoflurane was documented [39]. In long-term inhalational anesthesia comparing halothane with sevoflurane, only the sevoflurane group showed a transient significant increase in GSTA, making it a poorer choice for inhalation anesthesia in patients with mild liver dysfunction than halothane [40]. A safer course, given these findings is to avoid all inhalational agents (except nitrous oxide) in all patients with even minor impairment of liver function. Reports of liver necrosis after sevoflurane continue to be published [41]. Speculations about the pathophysiology of liver cell damage point at compound $\mathrm{A}$ as the culprit.

Sevoflurane is well established in clinical practice. All side effects are accepted by the vast majority of anesthesiologists because of the advantages of a more pleasant induction and an earlier emergence from anesthesia, as stormy as it might be. Why continue to argue about the above mentioned side effects?

The first reason is to refresh our awareness of these side effects, which apparently have been forgotten by many anesthesiologists, in particular the younger generation.

The second reason is that a fair number of countries cannot afford the use of sevoflurane on a daily basis because of its costs [42]. Does that mean that anesthesiologists in these poorer countries are practicing anesthesia of lower quality or even with less safety when using halothane?

By no means! These colleagues should not be discouraged! Halothane has a good safety record over more than 50 years, provided that overdosing is prevented and well known contraindications are avoided. It takes a few extra minutes for induction of anesthesia and emergence from anesthesia - with far less severe emergence agitation compared to sevoflurane [43]! If the regular dose of about three MAC (based on studies of one year old infants) is used for induction without additives, 2.7 vol\% of halothane is equivalent to 7.5 vol\% sevoflurane. Adding $60 \% \mathrm{~N}_{2} \mathrm{O}, 2.1$ vol\% halothane are equivalent to 6 vol\% sevoflurane. With these comparable doses, halothane and sevoflurane show the same hemodynamic depression in otherwise healthy patients. Again, it is more than surprising that the well known MAC-equivalences are rarely applied in the large body of published literature!

Scientifically proven advantages of sevoflurane remain the 
reasons for its use in arrhythmic patients and in those requiring subcutaneous adrenaline injections in plastic surgery. Whether children with congenital heart defects and cyanosis do profit from sevoflurane in comparison with halothane remains questionable since the study supporting this opinion [44] used up to 4.4 MAC halothane versus 3.2 MAC sevoflurane.

All inhalational agents except $\mathrm{N}_{2} \mathrm{O}$ are contraindicated in icteric ictal? Children, whereas $\mathrm{N}_{2} \mathrm{O}$ is the best choice of inhalational analgesia if there is difficulty obtaining i.v. access.

Inhalational anesthesia in pediatrics needs experienced anesthesiologists with a high awareness of the side effects of any anaesthetics currently available on the market. More detailed, epidemiological investigations are necessary to determine if sevoflurane has long term effects on the brain, in particular after a series of anesthetics.

Desflurane is infrequently used in pediatric anesthesia despite a very low blood-gas partition of 0.4 , causing very short emergence times even after long term application. Due to a high incidence of restlessness during emergence from anesthesia [45] and the difficulty in using it for mask induction, have kept many pediatric anesthesiologists from using it. However, airway events after desflurane anesthesia can be reduced considerably when children are extubated when they are awake [46].

\section{Intravenous Agents}

Remifentanil, the newest opioid marketed since 1996, is unique because an ester linkage allows rapid degradation by blood and tissue esterases. The very short half-life permits a rapid recovery, within 10 minutes, independent of hepatic or renal function [47].

Unlike all other opioids, the duration of action is independent of the administered dose and the duration of infusion, keeping the context sensitive half-life constant. This makes it an ideal agent for neonatal and infant anesthesia. There is no other drug than remifentanil with a greater clearance in neonates compared to older children [48].

Since remifentanil needs to be administered by continuous infusion, every interruption of the infusion or kinking of the intravenous line will quickly cause pain and possibly awareness. Postoperatively, pain management must be taken care of by regional blocks or other pain relieving medication.

Overdosing in the sense of toxicity is not possible; however, high doses cause bradycardia and hypotension, in particular when a bolus is given - which should therefore be avoided [49].

Chest rigidity, a typical opioid-related side effect that can prevent proper ventilation, is rarely encountered when bolusinjections are avoided. Several studies using remifentanil for intubation of neonates reported never having encountered chest wall rigidity when using up to $2 \mu \mathrm{g} / \mathrm{kg}$ [50]. Another study found chest wall rigidity in two out of 15 neonates when administering $3 \mu \mathrm{g} / \mathrm{kg}$ as a bolus within $60 \mathrm{sec}$, a rather high dose in a short period of time [51]. Chest wall rigidity seems to be related to dosing of remifentanil and appears to be a rare event.

Acute tolerance is suspected to occur during remifentanil infusion. In volunteers, analgesia was only one fourth of the initial peak level after three hours of continuous infusion [52]. This indicates that the dose needs to be increased during anesthesia according to the pain reactions of the patient.

Remifentanil alone is not sufficient as a sole anesthetic, even when given in higher doses, since it has no hypnotic effect. Propofol as a sole hypnotic is a good partner for remifentanil for short procedures and for diagnostic interventions without postoperative pain as after endoscopies. Intubation with $3 \mu \mathrm{g}$ remifentanil and $4 \mathrm{mg}$ propofol provided excellent intubation conditions and adequate analgesia. However, spontaneous respiration recurred later than with $1 \mu$ g remifentanil alone [53].

Propofol, a pure hypnotic agent, was released on the European market rather late in 1996 (in 1989 in the USA!) and gained immediate and wide spread acceptance in pediatric anesthesia because of rapid onset of anesthesia and quick emergence from anesthesia. This made it an almost ideal agent for short interventions with little or no postoperative pain such as that found during/after endoscopies. A great disadvantage of propofol for children is frequently appearing intense pain when it is injected intravenously, which can be reliably prevented only by inhalational induction. Significant drops in blood pressure with propofol induction or co-induction remain an important clinical problem today $[54,55]$. Due to its "popularity" it was uncritically used in high doses, often for long periods in intensive care units despite strict warnings based on pharmacokinetic data [56]. The result was the unnecessary, deplorable death of dozens of children and adults from propofol infusion syndrome (PRIS). Only a small fraction of these cases were reported in the literature according to my own experience [57]. It was thought that only doses higher than 4 $\mathrm{mg} / \mathrm{kg} / \mathrm{hr}$ and infusion periods greater than $48 \mathrm{hrs}$ caused this lethal side effect, but now there is evidence that far lower doses can be followed by PRIS [58,59]. The danger of PRIS is present today. These extremely dangerous side effects are practically all preventable by avoiding too high doses and by reacting immediately to early symptoms [60].

\section{Clonidine and dexmedetomidine}

Both drugs are alpha-2 agonists that may cause hypotension, bradycardia and somnolence in high doses. However, their sedative, anxiolytic, analgesic effects and the absence of respiratory depression make alpha-2 agonists very helpful 
drugs in pediatric anesthesia. Alpha-2 agonists, being used as analgesics and sedatives, are associated with an opioid sparing effect - typical opioid side effects such as respiratory depression, pruritus and urinary retention do not occur. For this reason, clonidine is frequently used as an adjunct to neuraxial block, with advantageous clinical results [61]. Clonidine is an old drug. Its analgesic properties have been used in pediatrics since 1977 [62].

Dexmedetomidine was released on the market in 1999 in the USA for adult use. Initial experiences with this drug in children, still being used off label, were published in 2002 [63]. Dexmedetomidine differs from clonidine by a greater alpha-2 receptor affinity, which results in shorter sedation times after ending an intravenous infusion, a more pronounced anti-shivering effect postoperatively, and a higher degree of arousability during long term sedation. The most frequent side effects are hypotension, bradycardia, nausea and significant hypertension when an initial dose is administered too rapidly [64]. The elimination half life of dexmedetomidine is about $2 \mathrm{hr}$, while it about $9 \mathrm{hr}$ for clonidine $[65,66]$.

Differentiating between these two similar drugs in order to provide the best clinical effects in any given case, cannot be done yet since convincing direct comparisons between the two drugs are missing. Dexmedetomidine as a new drug is far more intensely marketed than clonidine with arguments derived mainly from case reports. We as clinicians are in a conflict, as always, when being confronted with promising new drugs that are not well investigated in children. We would like to find a scientifically based, independent point of view. However, due to a lack of data we are prone to make mistakes, and in general, we should choose a careful approach to new drugs. This classical conflict has been described by well known pediatric anesthesiologists, possibly helping us to make appropriate decisions and not over-eagerly resort to new drugs [67-69]. The well known "old" drugs might have the same if not a better safety record.

At this point it seems that dexmedetomidine might have some advantages in short interventions in day care, and clonidine might have some advantages as an additive to regional blocks and long term sedation where easy arousability is not needed.

\section{Recently Developed Antagonists}

Flumazenil, an antagonist used in diazepine overdoses, has had an established place in pediatric anesthesia for about 20 years. Using it as routine antagonist in midazolamsupported anesthesia for target controlled anesthesia is rarely done anymore with the advent of propofol and remifentanil. However, it remains a safe mode of anesthesia.

Suggamadex, an antagonist of the long acting muscle relaxant rocuronium, is a very helpful new tool (on the market since 2008) in pediatric anesthesia. It reverses even an immediately administered relaxant without permitting a rebound effect. A high dose of rocuronium can be used for rapid sequence induction and be reversed within about one minute with a dose of $4.0 \mathrm{mg} / \mathrm{kg}$. When using $2.0 \mathrm{mg} / \mathrm{kg}$, three minutes are needed for reversal [70]. Suggamadex is still very expensive. Therefore, it is used only for well founded indications.

\section{Airway Care in Pediatric Anesthesia}

Dealing with delicate airways in infants and children is a very important part of pediatric anesthesia! A large body of literature and many presentations at international meetings have dealt with this problem. Unfortunately, the discussions are presently narrowed to the entirely unscientific slogan: "cuffed versus un-cuffed intubation" [71-74]. There is no "versus" position between different tubes per se, but an intense interest in identifying the least traumatic side effects of different brands and designs of tracheal tubes. This question was not convincingly answered by the above quoted studies since their outcome measure was simply inadequate. Dealing with airway injuries of different severity after intubation, it is obvious that ulcers, abrasions of the mucosa, and penetrating injuries on different anatomical levels (glottic, subglottic, tracheal) do not cause stridor as long as the lumen of the airway is not narrowed by $50 \%$. These sometimes dangerous injuries are not accessible to direct view and need to be evaluated by simple optical instruments (Hopkins or Bonfils lenses) in order to prevent the development of granulation tissue and later scarring and stenoses. Stridor cannot differentiate between benign injuries (temporary edema) or injuries needing an immediate surgical intervention. Endoscopy is needed for studying the effects of tracheal tubes in vivo; otherwise we will lose the most important information we need, a detailed description of possible injuries, whether they cause stridor or not.

In addition, an indispensable prerequisite for comparing tracheal tubes in humans was the design of the tubes (same outer diameters, cuffs of identical shape and position on the shaft). They had to be standardized before comparing tracheal tubes, which was not the case in any of the above mentioned studies.

If damage in a tunnel is suspected, specialists with good light sources are sent out to make visible what has happened to the walls or floor of the tunnel and to give a report. We need to do the same when the airway, a classical tunnel for the passage of air, has to be examined for possible damage.

The inadequacy of outcome measures for assessing airway injury was already addressed in 1987. They recommended airway endoscopy to initiate preventive treatment, e. g. anterior 
cricoid split, when airway injury was suspected [75]. In 1997, five children with subglottic stenosis due to intubation trauma were described. Only one $(20 \%)$ presented with stridor after extubation [76]. In 2005 it was noticed that not a single one of the studies designed to compare the incidence of airway trauma between children intubated with cuffed or un-cuffed tubes addressed subglottic stenosis, the worst side effect of airway injury. Since this is the worst complication of intubation, appearing late after the trauma, without the symptom of stridor, it should be the center of our concerns! This observation shows the inadequacy of all studies using stridor only as the only outcome measure! There is no rational reason for assuming that the absence of immediate post-extubation stridor excludes late subglottic stenosis [77].

This observation was supported in 2009 by two studies with an unusually large number of endoscopic documents, demonstrating that the mechanisms of airway injury were due to intubation and late scar development and were not accompanied by stridor $[78,79]$.

However, this ample evidence of the insufficiency of stridor as an outcome measure has not prevented further publications which still do not use the indispensable optical instruments (79). Such studies make comparisons between differently designed tracheal tubes impossible, and they thus prevent the acquisition of convincing results. It is not easy to answer the question why so many scientists in pediatric anesthesia are reluctant to use simple instruments to detect airway trauma as early as possible, in order to prevent late consequences for the patient. Is it a general fear of embarking on new technologies? Is it too difficult to imagine the value of endoscopic interventions, not having been exposed to airway endoscopy previously?

It is all the more remarkable that since the beginning of 2010 , several departments of pediatric anesthesia in ASEAN countries have embarked on using airway endoscopy to check for injuries on a regular basis. Lectures by external instructors and training in the operating rooms were part of this program. Mainly Hopkins and Bonfils lenses* were used since handling of these rigid instruments is far easier to learn and the quality of pictures considerably higher compared to the rather slow flexible fiberoptic endoscopy. (*Karl Storz GmbH \& Co-KG, Tuttlingen, Germany).

Lectures combined with training in the operating room show astounding immediate results. Practically all airway complications and injuries reported in the literature could be documented within a short time by endoscopy, such as injuries due to too large cuffed or uncuffed tubes, mucosal trauma by malpositioned cuffs, or folds of uninflated cuffs. Inflammation of ulcers or abrasions could be documented as evidence of older injuries that could not be detected without endoscopes. Unexpected malformations and narrowing of the airway could be detected early and expert help for intubation obtained.

[[Members of the respective teams thought this experience to be enlightening, making them independent of the current literature by observing side effects of intubation with their own eyes. MEANING IS UNCLEAR.]].

Thinking about advances in any medical field will always show progress accompanied by adverse effects that were not known before the advances. Knowing this rule, we have to be aware of unknown side effects when new drugs or techniques are introduce into clinical practice and we must use the novelties with great care.

\section{References}

1. ILCOR - Universal cardiac arrest model 2005. Circulation 2005; 112: III-1 - III-125. http://circ.ahajournals.org/content/vol112/22_ suppl/

2. Perondi MB, Reis AG, Paiva EF, Nadkarni VM, Berg RA. A comparison of high-dose and standard-dose epinephrine in children with cardiac arrest. N Engl J Med 2004; 350: 1722-30.

3. Todres ID, Fugate JH. Critical Care for infants and children. Newyork, Little Brown \& Co. 1996.

4. Goetting MG, Paradis NA. High-dose epinephrine improves outcome from pediatric arrest. Ann Emerg Med 1991; 20: 22-6.

5. Bjørshol CA, Søreide E, Torsteinbø TH, Lexow K, Nilsen OB, Sunde K. Quality of chest compressions during $10 \mathrm{~min}$ of single-rescuer basic life support with different compression: ventilation ratios in a manikin model. Resuscitation 2008; 77: 95-100.

6. Vento M, Saugstad OD. Resuscitation of the term and preterm infant. Semin Fetal Neonatal Med 2010; 15: 216-22.

7. Dalens B. Regional anesthesia in pediatrics. Ann Fr Anesth Reanim 1989; 8: 51-66

8. Thomas JM, Schug SA. Recent advances in the pharmacokinetics of local anesthetics. Long-acting amide enantiomers and continuous infusion. Clin Pharmacokinet 1999; 36: 67-83.

9. Karmakar MK, Kwok WH. A Practice of Anesthesia for Infants and Children. Ultrasound-Guided Regional Anesthesia. 4th ed. Edited by Coté CJ, Lerman J, Todres D. Philadelphia, Saunders Elsevier. 2009, pp 911-38.

10. Flandin-Bléty C, Barrier G. Accidents following extradural anesthesia in children. The results of a retrospective study. Paediatr Anaesth 1995; 5: 41-6.

11. Giaufre E, Dalens B, Gombert A. Epidemiology and morbidity of regional anesthesia in children: a one-year prospective survey of the French-Language Society of Pediatric Anesthesiologists. Anesth Analg 1996; 83: 904-12.

12. Tsui BC. Innovative approaches to neuraxial blockade in children: the introduction of epidural nerve root stimulation and ultrasound guidance for epidural catheter placement. Pain Res Manag 2006; 11: $173-80$.

13. Tsui BC, Suresh S. Ultrasound imaging for regional anesthesia in infants, children and adolescents: a review of current literature and its application in the practice of neuraxial blocks. Anesthesiology 2010; 112: 719-28

14. Eger EI 2nd, Saidman LJ, Brandstater B. Minimum alveolar anesthetic 
concentration: a standard of anesthetic potency. Anesthesiology 1965; 26: 756-63.

15. Paul M, Fisher DM. Are estimates of MAC reliable? Anesthesiology 2001; 95: 1362-70.

16. Coté CJ, Lerman J, Ward RM, Lugo RA, Goudsouzian N. A Practice of Anesthesia for Infants and Children. Pharmacokinetics and Pharmakology of Drugs Used in Children. 4th ed. Edited by Coté CJ, Lerman J, Todres D. Philadelphia, Saunders Elsevier. 2009, pp 100-19.

17. Maruyama K, Agata H, Ono K, Hiroki K, Fujihara T. Slow induction with sevoflurane was associated with complete atrioventricular block in a child with hypertension, renal dysfunction, and impaired cardiac conduction. Paediatr Anaesth 1998; 8: 73-8.

18. Driessen JJ, van Oort AM, Booij LH. Severe myocardial ischaemia during mask induction of anaesthesia in an infant with unknown critical supravalvular aortic stenosis. Anaesthesia 2003; 58: 568-70.

19. Piat V, Dubois MC, Johanet S, Murat I. Induction and recovery characteristics and hemodynamic responses to sevoflurane and halothane in children. Anesth Analg 1994;79: 840-4.

20. Epstein RH, Stein AL, Marr AT, Lessin JB. High concentration versus incremental induction of anesthesia with sevoflurane in children: a comparison of induction times, vital signs, and complications. J Clin Anesth 1998; 10: 41-5.

21. Nakae Y, Miyabe M, Sonoda H, Kawana S, Namiki A. Comparison of intubating condition under sevoflurane and halothane anesthesia in pediatric patients. Masui 1995; 44: 239-43.

22. Sarner JB, Levine M, Davis PJ, Lerman J, Cook DR, Motoyama EK. Clinical characteristics of sevoflurane in children: a comparison with halothane. Anesthesiology 1995; 82: 38-46.

23. Lerman J, Davis PJ, Welborn LG, Orr RJ, Rabb M, Carpenter R, et al. Induction, recovery, and safety characteristics of sevoflurane in children undergoing ambulatory surgery: a comparison with halothane. Anesthesiology 1996; 84: 1332-40.

24. Sigston PE, Jenkins AM, Jackson EA, Sury MR, Mackersie AM, Hatch DJ. Rapid inhalation induction in children: $8 \%$ sevoflurane compared with 5\% halothane. Br J Anaesth 1997; 78: 362-5.

25. Holzki J, Kretz FJ. Changing aspects of sevoflurane in paediatric anaesthesia: 1975-99. Paediatr Anaesth 1999; 9: 283-6.

26. Coté CJ, Lerman J, Ward RM, Lugo RA, Goudsouzian N. A Practice of Anesthesia for Infants and Children. Pharmacokinetics and Pharmakology of Drugs Used in Children. 4th ed. Edited by Coté CJ, Lerman J, Todres ID. Philadelphia, Saunders Elsevier. 2009, p 105.

27. Bhananker SM, Ramamoorthy C, Geiduschek JM, Posner KL, Domino KB, Haberkern CM, et al. Anesthesia-related cardiac arrest in children: update from the Pediatric Perioperative Cardiac Arrest Registry. Anesth Analg 2007; 105: 344-50.

28. Paris ST, Cafferkey M, Tarling M, Hancock P, Yate PM, Flynn PJ. Comparison of sevoflurane and halothane for outpatient dental anaesthesia in children. Br J Anaesth 1997; 79: 280-4.

29. Coté CJ, Lerman J, Ward RM, Lugo RA, Goudsouzian N. A Practice of Anesthesia for Infants and Children. Pharmacokinetics and Pharmakology of Drugs Used in Children. 4th ed. Edited by Coté CJ, Lerman J, Todres ID. Philadelphia, Saunders Elsevier. 2009, p 108.

30. Wodey E, Pladys P, Copin C, Lucas MM, Chaumont A, Carre P, et al. Comparative hemodynamic depression of sevoflurane versus halothane in infants: an echcardiographic study. Anesthesiology 1997; 87: 795-800.
31. Haga S, Shima T, Momose K, Andoh K, Hashimoto Y. Anesthetic induction of children with high concentrations of sevoflurane. Masui 1992; 41: 1951-5.

32. Yli-Hankala A, Vakkuri A, Särkelä M, Lindgren L, Korttila K, Jäntti V. Epileptiform electroencephalogram during mask induction of anesthesia with sevoflurane. Anesthesiology 1999; 91: 1596-603.

33. Kaisti KK, Jääskeläinen SK, Rinne JO, Metsähonkala L, Scheinin H. Epileptiform discharges during 2 MAC sevoflurane anesthesia in two healthy volunteers. Anesthesiology 1999; 91: 1952-5.

34. Vakkuri A, Yli-Hankala A, Särkelä M, Lindgren L, Mennander S, Korttila K, et al. Sevoflurane mask induction of anaesthesia is associated with epileptiform EEG in children. Acta Anaesthesiol Scand 2001; 45: 805-11.

35. Jääskeläinen SK, Kaisti K, Suni L, Hinkka S, Scheinin H. Sevoflurane is epileptogenic in healthy subjects at surgical levels of anesthesia. Neurology 2003; 61: 1073-8.

36. Constant I, Seeman R, Murat I. Sevoflurane and epileptiform EEG changes. Paediatr Anaesth 2005; 15: 266-74.

37. Särkelä MO, Ermes MJ, van Gils MJ, Yli-Hankala AM, Jäntti VH, Vakkuri AP. Quantification of epileptiform electroencephalographic activity during sevoflurane mask induction. Anesthesiology 2007; 107: 928-38.

38. Voss LJ, Sleigh JW, Barnard JP, Kirsch HE. The howling cortex: seizures and general anesthetic drugs. Anesth Analg 2008; 107: 1689-703.

39. Shichinohe Y, Masuda Y, Takahashi H, Kotaki M, Omote T, Shichinohe $\mathrm{M}$, et al. A case of postoperative hepatic injury after sevoflurane anesthesia. Masui 1992; 41: 1802-5.

40. Iwanaga Y, Komatsu H, Yokono S, Ogli K. Serum glutathione S-transferase alpha as a measure of hepatocellular function following prolonged anaesthesia with sevoflurane and halothane in paediatric patients. Paediatr Anaesth 2000; 10: 395-8.

41. Singhal S, Gray T, Guzman G, Verma A, Anand K. Sevoflurane hepatotoxicity: a case report of sevoflurane hepatic necrosis and review of the literature. Am J Ther 2010; 17: 219-22.

42. Bösenberg AT, Murat I. A Practice of Anesthesia for Infants and Children. Pediatric anesthesia in developing countries. 4th ed. Edited by Coté CJ, Lerman J, Todres D. Philadelphia, Saunders Elsevier. 2009, pp 1077-84.

43. Cravero J, Surgenor S, Whalen K. Emergence agitation in paediatric patients after sevoflurane anaesthesia and no surgery: a comparison with halothane. Paediatr Anaesth 2000; 10: 419-24.

44. Russell IA, Miller Hance WC, Gregory G, Balea MC, Cassorla L, DeSilva A, et al. The safety and efficacy of sevoflurane anesthesia in infants and children with congenital heart disease. Anesth Analg 2001; 92: 1152-8.

45. Cohen IT, Hannallah RS, Hummer KA. The incidenceof emergence agitation associated with deflurane anesthesia in children. Anesth Analg 2001; 93: 88-91.

46. Lerman J, Hammer GB, Verghese S, Ehlers M, Khalil SN, Betts E, et al. Airway responses to desflurane during maintenance of anesthesia and recovery in children with laryngeal mask airways. Paediatr Anaesth 2010; 20: 495-505.

47. Rosow C. Remifentanil: a unique opioid analgesic. Anesthesiology 1993; 79: 875-6.

48. Akpek EA, Erkaya C, Donmez A, Mercan S, Esen A, Aslamaci S, et al. 
Remifentanil use in children undergoing congenital heart surgery for left-to-right shunt lesions. J Cardiothorac Vasc Anesth 2005; 19: 60-6.

49. Ross AK, Davis PJ, Dear Gd GL, Ginsberg B, McGowan FX, Stiller $\mathrm{RD}$, et al. Pharmacokinetics of remifentanil in anesthetized pediatric patients undergoing elective surgery or diagnostic procedures. Anesth Analg 2001; 93: 1393-401.

50. Crawford MW, Hayes J, Tan JM. Dose-response of remifentanil for tracheal intubation in infants. Anesth Analg 2005; 100: 1599-604.

51. Choong K, AlFaleh K, Doucette J, Gray S, Rich B, Verhey L, et al. Remifentanil for endotracheal intubation in neonates: a randomised controlled trial. Arch Dis Child Fetal Neonatal Ed 2010; 95: F80-4.

52. Vinik HR, Kissin I. Rapid development of tolerance to analgesia during remifentanil infusion in humans. Anesth Analg 1998; 86: 1307-11.

53. Blair JM, Hill DA, Wilson CM, Fee JP. Assessment of tracheal intubation in children after induction with propofol and different doses of remifentanil. Anaesthesia 2004; 59: 27-33.

54. Nafiu OO, Kheterpal S, Morris M, Reynolds PI, Malviya S, Tremper KK. Incidence and risk factors for preincision hypotension in a noncardiac pediatric surgical population. Paediatr Anaesth 2009; 19: 232-9.

55. Kanto J, Gepts E. Pharmacokinetic implications for the clinical use of propofol. Clin Pharmacokinet 1989; 17: 308-26.

56. Holzki J, Aring C, Gillor A. Death after re-exposure to propofol in a 3-year-old child: a case report. Paediatr Anaesth 2004;14: 265-70.

57. Kill C, Leonhardt A, Wulf H. Lacticacidosis after short-term infusion of propofol for anaesthesia in a child with osteogenesis imperfect. Paediatr Anaesth 2003; 13: 823-6.

58. Chukwuemeka A, Ko R, Ralph-Edwards A. Short-term low-dose propofol anaesthesia associated with severe metabolic acidosis. Anaesth Intensive Care 2006; 34: 651-5.

59. Laquay N, Prieur S, Greff B, Meyer P, Orliaguet G. Propofol infusion syndrome. Ann Fr Anesth Reanim 2010; 29: 377-86

60. Ivani G, De Negri P, Conio A, Amati M, Roero S, Giannone S, et al. Ropivcacaine-clonidine combination for caudal blockade in children. Acta Anaesthesiol Scand 2000; 44: 446-9.

61. Sillanpää M. Clonidine prophylaxis of childhood migraine and other vascular headache. a double blinded study of 57 children; Headache 1977; 17: 28-31.

62. Tobias JD, Berkenbosch JW. Initial experience with dexmedetomidine in paediatric-aged patients. Paediatr Anaesth 2002; 12: 1715.

63. Bhana N, Goa KL, McClellan KJ. Dexmedetomidine. Drugs 2000; 59: 263-8.

64. Vilo S, Rautiainen P, Kaisti K, Aantaa R, Scheinin M, Manner T, et al. Pharmacokinetics of intravenous dexmedetomidine in children under 11 yr of age. Br J Anaesth 2008; 100: 697-700.

65. Potts AL, Larsson P, Eksborg S, Warman G, Lönnqvist PA, Anderson BJ. Clonidine disposition in children; a population analysis. Paediatr Anaesth 2007; 17: 924-33.

66. Petroz GC, Sikich N, James M, van Dyk H, Shafer SL, Schily M, et al. A phase I, two-center study of the pharmacokinetics and pharmacodynamics of dexmedetomidine in children. Anesthesiology 2006; 105: 1098-110.

67. Tobin JR, Shafer SL, Davis PJ. Pediatric research and scholarship: another Gordian knot? Anesth Analg 2006; 103: 43-8.

68. Fisher D. Do the right thing (or Do the market exclusivity thing?). Anesthesiology 2006; 105: 1074-5.

69. Sorgenfrei IF, Norrild K, Larsen PB, Stensballe J, Ostergaard D, Prins ME, et al. Reversal of rocuronium-induced neuromuscular block by the selective relaxant binding agent sugammadex: a dose-finding and safety study. Anesthesiology 2006; 104: 667-74.

70. Khine HH, Corddry DH, Kettrick RG, Martin TM, McCloskey JJ, Rose JB, et al. Comparion of cuffed and uncuffed endotracheal tubes in young children during general anesthesia. Anesthesiology 1997; 86: 627-31.

71. Fisher DM. Highlight: comparison of cuffed and uncuffed endotracheal tubes in young children during general anesthesia. Anesthesiology 1997; 86V: 27A.

72. Newth CJ, Rachman B, Patel N, Hammer J. The use of cuffed vs uncuffed endotracheal tubes in intensive care. J Pediatr 2004; 144: 333-7.

73. Deakers TW, Reynolds G, Stretton M, Newth CJ. Cuffed endotracheal tubes in pediatric intensive care. J Pediatr 1994; 125: 57-62.

74. Dubreuil C. Laryngotracheal stenosis in children. Pediatrie 1987; 42: 273-9.

75. Wiel E, Vilette B, Darras JA, Scherpereel P, Leclerc F. Larngotracheal stenosis in children after intubation. Report of five cases. Paediatr Anaesth 1997; 7: 415-9.

76. Ashtekar CS, Wardhaugh A. Do cuffed endotracheal tubes increase the risk of airway mucosal injury and post-extubation stridor in children? Arch Dis Child 2005; 90: 1198-9.

77. Holzki J, Laschat M, Puder C. Stridor is not a scientifically valid outcome measure for assessing airway injury. Paediatr Anaesth 2009; 19(Suppl 1): 180-97.

78. Holzki J, Laschat M, Puder C. Iatrogenic damage to the pediatric airway. Mechanisms and scar development. Paediatr Anaesth 2009; 19(Suppl 1): 131-46.

79. Weiss M, Dullenkopf A, Fischer JE, Keller C, Gerber AC; European Paediatric Endotracheal Intubation Study Group. Prospective randomized controlled multi-centre trial of cuffed or uncuffed endotracheal tubes in small children. Br J Anaesth 2009; 103: 86773. 